\title{
KESIAPAN TENAGA KESEHATAN MASYARAKAT (SARJANA KESEHATAN MASYARAKAT) UNTUK BERMITRADENGAN FASILITAS KESEHATAN TINGKAT PERTAMA DALAM UPAYA PROMOTIF DAN PREVENTIF
}

\author{
${ }^{1}$ Rossi Suparman, ${ }^{2}$ Ade Saprudin, ${ }^{2}$ Cecep Heriana \\ ${ }^{1}$ IAKMI Kabupaten Kuningan \\ ${ }^{2}$ Sekolah Tinggi Ilmu Kesehatan Kuningan garawangi \\ cecepheriana@gmail.com
}

\begin{abstract}
Pelayanan kesehatan dalam Pelaksanaan JKN di Indonesia terdiri dari Promotif, Preventif, kuratif dan rehabilitatif, namun pada pelaksanaannya pelayanan promotif dan preventif oleh FKTP belum dilaksanakan secara optimal, salah satunya disebabkan karena tidak tersedia Tenaga Kesehatan Masyarakat. Tenaga Kesehatan Masyarakat atau Sarjana Kesehatan Masyarakat (SKM) dapat bermitra dengan FKTP untuk melaksanakan upaya promotif dan preventif dengan persyaratan tenaga kesehatan masyarakat harus siap melaksanakan kemitraan sebagai implementasi praktik kesehatan masyarakat. Sampai dengan saat ini tidak tersedia data tentang kesiapan tenaga kesehatan masyarakat untuk bermitra dengan FKTP. Tujuan penelitian untuk mengetahui gambaran kesiapan Tenaga Kesehatan Masyarakat/SKM yang mandiri untuk bermitra dengan FKTP di Kab. Kuningan. Hasil penelitian menunjukan bahwa sebanyak $80 \%$ responden tidak memiliki STR, sebanyak $85 \%$ belum menjadi anggota IAKMI, 90\% tidak memiliki pengalaman bermitra dengan FKTP. Sebanyak 100 persen SKM siap bermitra dengan FKTP dan memiliki kepercayaan diri atas kompetensinya. Kesimpulan bahwa sebagian besar tidak memiliki STR, bukan anggota IAKMI, pengetahuan baik, tidak memiliki pengalaman bermitra dan memiliki kepercayaan diri. Saran diharapkan SKM meningkatkan kompetensi untuk mendapatkan STR dan tergabung dalam organisasi profesi IAKMI dan bagi IAKMI dan AIPTKMI harus menyusun panduan praktik kesehatan masyarakat dan kemitraan dengan FKTP sebagai bagian dari praktik mandiri kesehatan masyarakat.
\end{abstract}

Kata Kunci : Kesiapan, SKM, FKTP, Promotif, Preventif

\section{Pendahuluan}

Pelaksanaan Jaminan Kesehatan Nasional di Indonesia dimulai sejak tanggal 1 Januari 2014 yang dilandasi oleh amanat Undang-Undang Dasar 1945, Undang Undang nomor 40 tahun 2004 tentang Sistem Jaminan Sosial Nasional dan Undang-Undang nomor 24 tahun 2011 tentang Badan Penyelenggaraan Jaminan Sosial (BPJS). Di era Jaminan Kesehatan Nasional (JKN) pelayanan kesehatan tidak lagi terpusat di rumah sakit atau fasilitas kesehatan (faskes) tingkat lanjutan, namun pelayanan kesehatan harus dilakukan secara berjenjang sesuai dengan kebutuhan medisnya (Vijriyanti, 2018). Hal ini dimaksudkan untuk meningkatkan kualitas pelayanan bagi peserta BPJS Kesehatan. Dalam implementasi sistem jaminan kesehatan nasional prinsip manage care diberlakukan, dimana terdapat 4 (empat) pilar yaitu promotif, preventif, kuratif dan rehabilitatif. Prinsip ini akan 
JURNAL ILMU KESEHATAN BHAKTI HUSADA:

HeALTH SCIENCES JOURNAL, Vol. 10 No. 02, DeSEMBER 2019

DOI: $10.34305 / J I K B H . V 10 I 2.98$

memberlakukan pelayanan kesehatan akan difokuskan di pelayanan Kesehatan Tingkat Pertama ( FKTP) / Faskes primer seperti puskesmas, klinik atau dokter praktek perorangan yang akan menjadi gerbang utama peserta BPJS Kesehatan dalam mengakses pelayanan kesehatan (Betri Anita, Henni Febriawati, 2019). Pelayanan promotif dan preventif merupakan salah satu indikator pelayanan yang wajib dilaksanakan Fasilitas Kesehatan Tingkat Pertama (FKTP) yang berperan sebagai gatekeeper dalam pemanfaatan pelayanan kesehatan pada era Jaminan Kesehatan Nasional (JKN) (A. Rahma, S. Arso, 2017). Pelayanan kesehatan promotif adalah suatu kegiatan dan/atau serangkaian kegiatan pelayanan kesehatan yang lebih mengutamakan kegiatan bersifat promosi kesehatan. Sementara itu, pelayanan kesehatan preventif adalah suatu kegiatan pencegahan terhadap suatu masalah kesehatan/penyakit. Pelayanan promotif dan preventif ini bertujuan untuk mencegah dan menurunkan angka kesakitan. Namun dalam implementasinya, pelayanan promotif dan preventif justru tidak dijalankan dengan maksimal. Hasil penelitian Pelaksanaan pelayanan promotif preventif di era JKN di Puskesmas Bungus pada tahun kedua pelaksanaannya terjadi peningkatan. Hanya saja pada kegiatan penyuluhan kesehatan dan skrining masih belum terlaksana dengan baik (Atia, 2015). Salah satu kendala mengapa upaya promotif dan preventif di FKTP yang kurang berjalan dengan baik karena minimnya tenaga kesehatan dan kompetensi yang masih kurang,sehingga FKTP fokus pada pelayanan kuratif dan rehabilitatif (Ratih Kumala Dewi, Nuryadi, 2016) (Yuniar, 2016). Tenaga kesehatan yang memiliki kompetensi utama dalam upaya Promotif dan preventif adalah tenaga kesehatan masyarakat (AIPTKMI, 2012). Tenaga Kesehatan Masyarakat atau Sarjana Kesehatan masyarakat (SKM) merupakan sumber daya manusia yang sangat penting perannya guna meningkatkan kesadaran
Ciptaan disebarluaskan di bawah

Lisensi Creative Commons Atribusi-

NonKomersial-BerbagiSerupa 4.0

Internasional.

yang lebih tinggi pada pelayanan kesehatan yang bersifat promotif dan preventif (Supratman Sukowati, 2003). Kompetensi utama SKM yaitu mengkaji dan menganalisis situasi kesehatan masyarakat, mengembangkan dan merancang kebijakan dan program kesehatan, berkomunikasi secara efektif, memahami budaya setempat, memberdayakan masyarakat, menguasai dasar-dasar ilmu kesehatan masyarakat, perencanaan keuangan dan keterampilan manajerial dan mampu memimpin dan berfikir sistem bagian (AIPTKMI, 2012).

SKM supaya dapat terlibat di FKTP termasuk diantaranya dengan Dokter Keluarga maka dapat dilaksanakan melalui kemitraan. Kemitraan dapat terjalin apabila kedua belah pihak memiliki kesiapan untuk bermitra dan keuntungan dari hasil kemitraan. Tidak tersedia data tentang kesiapan tenaga kesehatan masyarakat untuk bermitra dengan FKTP. Berdasarkan fenomena diatas maka tujuan dari penelitian ini untuk mengetahui gambaran tentang kesiapan Tenaga Kesehatan Masyarakat (Sarjana Kesehatan Masyarakat) dalam Bermitra dengan Fasilitas Kesehatan Tingkat Pertama (FKTP)".

\section{Bahan dan Metode}

Jenis penelitian Deskriptif dengan pendekatan survei, untuk mengetahui kesiapan tenaga kesehatan dalam melaksanakan praktik kesehatan masyarakat bermitra dengan FKTP sesuai dengan kompetensi dan kewenangan tenaga kesehatan masyarakat. Ada dua variabel utama yang digunakan dalam penelitian ini yaitu karakteristik tenaga kesehatan masyarakat yang terdiri dari kepemilikan STR Ahli Kesehatan Masyarakat dan Keanggotan Organisasi Profesi IAKMI, kemudian untuk kesiapan tenaga kesehatan masyarakat praktik dengan bermitra dengan FKTP yaitu pengetahuan praktik mandiri, pengalaman bermitra dengan FKTP, kesiapan bermitra dengan FKTP dan Kepercayaan diri SKM terhadap 
JURNAL ILMU KESEHATAN BHAKTI HUSADA:

HEALTH SCIENCES JOURNAL, Vol. 10 No. 02, DeSEMBER 2019

DOI: $10.34305 / J I K B H . V 10 I 2.98$

kompetensi yang dimiliki. Penelitian ini dilaksanakan pada bulan Juni-Agustus 2019 dengan responden yang dipilih adalah para tenaga kesehatan Masyarakat (SKM) yang mandiri tidak terikat dengan instansi pelayanan kesehatan (tingkat primer dan sekunder) yang berdomisili di Kabupaten Kuningan sebanyak 20 orang. Data dan Informasi yang diperlukan dalam penelitian ini untuk mengakses variabel penelitian diaplikasikan dalam pertanyaan-pertanyaan survei atau kuesioner, dan dikelompokkan pada tingkatan kesiapan dengan analisis data deskriptif.
Ciptaan disebarluaskan di bawah

Lisensi Creative Commons Atribusi-

NonKomersial-BerbagiSerupa 4.0

Internasional.

Hasil

Penelitian ini dimulai dengan identifikasi praktisi kesehatan masyarakat atau Sarjana Kesehatan Masyarakat (SKM) yang mandiri di 36 wilayah Puskesmas tempat penelitian dilakukan. Wawancara dengan tenaga kesehatan masyarakat (SKM) yang mandiri yaitu menggunakan kuesioner. Berdasarkan hasil survei tenaga kesehatan masyarakat yang tidak terikat dengan FKTP di Kabupaten Kuningan didapatkan responden sebanyak 20 orang. Berikut hasil penelitian tahap diagnosis yang telah dilakukan :

\section{Identitas dan karakteristik Responden}

Tabel 1. Karakteristik Responden

\begin{tabular}{|c|c|c|c|c|}
\hline No & \multicolumn{2}{|c|}{ Karakteristik } & Jumlah (n) & Presentase (\%) \\
\hline \multirow[t]{2}{*}{1} & \multirow{2}{*}{ Kepemilikan STR } & $\mathrm{Ya}$ & 6 & 30 \\
\hline & & Tidak & 14 & 70 \\
\hline \multirow[t]{2}{*}{2} & \multirow{2}{*}{$\begin{array}{l}\text { Keanggotan Organisasi } \\
\text { profesi IAKMI }\end{array}$} & $\begin{array}{c}\text { Sudah Menjadi } \\
\text { Anggota }\end{array}$ & 3 & 15 \\
\hline & & $\begin{array}{l}\text { Belum menjadi } \\
\text { Anggota }\end{array}$ & 17 & 85 \\
\hline
\end{tabular}

Berdasarkan tabel 1 diatas, bahwa sebanyak 6 orang (30\%) responden memiliki STR Ahli Kesehatan Masyarakat dan sebanyak 14 orang $(70 \%)$ tidak memiliki STR Ahli Kesehatan Masyarakat. Sedangkan untuk keanggotaan Organisasi
Profesi Kesehatan Masyarakat sebanyak 3 orang $(15 \%)$ telah menjadi anggota dan sebanyak 17 orang $(85 \%)$ belum terdaftar menjadi anggota Organisasi Profesi Kesehatan Masyarakat yaitu Ikatan Ahli Kesehatan Masyarakat Indonesia (IAKMI).

\section{Kesiapan praktik mandiri kemitraan SKM dengan FKTP}

Tabel 2. Kesiapan praktik mandiri SKM dan bermitra dengan FKTP

\begin{tabular}{ccccc}
\hline No & \multicolumn{2}{c}{ Variabel } & Jumlah & Presentase \\
\hline 1 & $\begin{array}{c}\text { Pengetahuan Praktik } \\
\text { mandiri }\end{array}$ & Mengetahui & 4 & 20 \\
\cline { 3 - 5 } & & Tidak & 16 & 80 \\
\hline 2 & $\begin{array}{c}\text { Pengalaman Bermitra } \\
\text { dengan FKTP }\end{array}$ & Pengalaman & 2 & 10 \\
\cline { 3 - 5 } & $\begin{array}{c}\text { Kesediaan menjadi } \\
\text { Mitra FKTP }\end{array}$ & Tidak pengalaman & 18 & 90 \\
\hline 3 & $\begin{array}{c}\text { Kepercayan Diri atas } \\
\text { Kompetensi }\end{array}$ & Percaya Diri & 20 & 100 \\
\hline 4 & & 20 & 100 \\
\hline
\end{tabular}

Berdasarkan tabel 2 di atas pengetahuan responden tentang praktik mandiri kesehatan masyarakat sebanyak 4 orang (20\%) responden mengetahui bagaimana praktik kesehatan masyarakat dapat dilaksanakan dan sebagian besar yaitu 16 orang $(80 \%)$ tidak mengetahui praktik mandiri kesehatan masyarakat. Variabel OPEN@ACCESS
Pengalaman bermitra dengan FKTP menunjukkan sebanyak 2 orang (10\%) responden pernah bermitra dan bekerjasama dengan FKTP dan sebagian besar yaitu 18 orang $(80 \%)$ tidak pernah bekerjasama dan bermitra dengan FKTP. Sedangkan untuk variabel kesediaan dan kesiapan SKM menjadi Mitra FKTP sebagai bentuk praktik E-ISSN 2623-1204 P-ISSN 2252-9462 | 124 
JURNAL ILMU KESEHATAN BHAKTI HUSADA:

HEALTH SCIENCES JOURNAL, Vol. 10 No. 02, DeSEMBER 2019

DOI: $10.34305 / J I K B H . V 10 I 2.98$

mandiri kesehatan masyarakat menunjukan semuanya $(100 \%)$ bersedia untuk bermitra apabila terdapat kesempatan. Kemudian untuk kepercayaan diri atas kompetensi SKM yang dimiliki semuanya (100\%) menyatakan percaya diri akan kompetensi yang dimiliki untuk melaksanakan upayaupaya kesehatan masyarakat.

\section{Diskusi}

\section{Registrasi dan Organisasi Profesi Tenaga Kesehatan Masyarakat}

Tenaga kesehatan masyarakat adalah setiap orang yang mengabdikan diri dalam bidang kesehatan masyarakat serta memiliki pengetahuan dan atau keterampilan melalui pendidikan di bidang kesehatan masyarakat. Tenaga Kesehatan Masyarakat diatur dalam Undang-undang No. 36 Tahun 2014 tentang Tenaga Kesehatan yang harus terdata atau teregistrasi sebagai tenaga kesehatan melalui Surat Tanda Registrasi yang dikeluarkan oleh Majelis Tenaga Kesehatan Indonesia (MTKI) (Undang-undang, 2014). STR Tenaga Kesehatan Masyarakat dibagi menjadi 3 (tiga) kelompok yaitu STR Ahli Kesehatan Masyarakat Pratama, Madya Utama (AIPTKMI, 2012). Persyaratan Pendidikan untuk mendapat STR tenaga Kesehatan Masyarakat Pratama adalah minimal pendidikan Sarjana Kesehatan Masyarakat (SKM) yang diluluskan dari Program Studi Kesehatan Masyarakat jenjang Strata-1. Berdasarkan UU. No.36 Tahun 2014 semua tenaga Kesehatan wajib memiliki STR yang diberikan pada SKM dengan ketentuan bahwa SKM yang lulusan sebelum dan sampai tahun 2014 maka untuk mendapatkan STR dengan persyaratan Ijazah atau tanpa Uji Kompetensi sedangkan SKM yang lulusan setelah tahun 2014 maka harus mengikuti Uji Kompetensi. Uji Kompetensi dalam bidang Kesehatan Masyarakat disebut Uji Kompetensi Ahli Kesehatan Masyarakat (UKAKM) yang dilaksanakan oleh Panitia

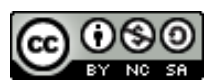

Nasional yang dibentuk oleh organisasi profesi Kesehatan Masyarakat sebagai anggota MTKI yaitu Ikatan Ahli Kesehatan Masyarakat Indonesia (IAKMI) dan Asosiasi Institusi Pendidikan Tinggi Kesehatan Masyarakat Indonesia (AIPTKMI). Berdasarkan hasil penelitian menunjukan bahwa lulusan SKM yang tidak terikat dengan Fasilitas Kesehatan Tingkat Pertama di Kabupaten Kuningan sebanyak $30 \%$ yang sudah memiliki STR dan sebanyak $70 \%$ belum memiliki STR, dengan demikian SKM yang tidak memiliki STR tidak dapat melaksanakan praktik. Sebagaimana menurut Undang-Undang No 36 tahun 2014 bahwa STR ini digunakan sebagai persyaratan tenaga kesehatan masyarakat untuk melakukan Praktik Kesehatan Masyarakat. Jenis Tenaga kesehatan Masyarakat menurut Undangundang No 36 Tahun 2014 disebutkan bahwa jenis tenaga kesehatan yang termasuk dalam kelompok tenaga kesehatan masyarakat terdiri dari Epidemiolog Kesehatan, Tenaga Promosi Kesehatan dan Ilmu Perilaku, Pembimbing Kesehatan Kerja, Tenaga Administrasi dan Kebijakan Kesehatan, Tenaga Biostatistik dan Kependudukan, serta Tenaga Kesehatan Reproduksi dan Keluarga. Berdasarkan hasil penelitian hanya $15 \%$ SKM yang sudah menjadi anggota organisasi Profesi IAKMI hal ini menunjukan bahwa SKM belum memiliki motivasi kuat untuk menjadi bagian dari organisasi profesi sebagai wadah untuk melaksanakan Praktik Profesional Kesehatan Masyarakat. Praktek kesehatan masyarakat ini diatur oleh Organisasi Profesi Kesehatan Masyarakat IAKMI berdasarkan Kode Etik Profesi Kesehatan Masyarakat Indonesia yang menyatakan bahwa Ahli Kesehatan Masyarakat senantiasa berusaha untuk meningkatkan pengetahuan dan keterampilannya sesuai dengan perkembangan ilmu pengetahuan dan teknologi (IAKMI, 2018). 
JURNAL ILMU KESEHATAN BHAKTI HUSADA:

HEALTH SCIENCES JOURNAL, Vol. 10 No. 02, DeSEMBER 2019

DOI: $10.34305 / J I K B H . V 10 I 2.98$

\section{Kesiapan Tenaga Kesehatan Masyarakat bermitra dengan FKTP}

Kesiapan atau readiness berasal dari bidang studi Psikologi, yang menyatakan bahwa kesiapan adalah suatu keadaan seseorang, sistem atau organisasi untuk memenuhi situasi dan melaksanakan urutan tindakan yang direncanakan (businessdictionary) (Bruner, 1957). Kesiapan komunitas adalah sejauh mana komunitas bersedia dan siap untuk mengambil tindakan terhadap suatu masalah karena kesiapan ini menjadi faktor utama dalam menentukan apakah suatu program (Edwards, Jumper-Thurman, Plested, Oetting, \& Swanson, 2000). Kondisi kesiapan orang, sistem, atau organisasi untuk memenuhi situasi dan melaksanakan urutan tindakan yang direncanakan dan didasarkan pada ketelitian dari perencanaan, kecukupan dan pelatihan personil, dan pasokan dan cadangan layanan dukungan atau sistem

Kesiapan merupakan keadaan atau status psikologis yang bisa dikembangkan dari tingkat yang rendah hingga tingkatan yang lebih dewasa atau matang (J. Sudirwan, 2015). Merujuk pada Personal Readiness for Change dalam Community Readyness for Community Chage Linda R. Stanley (2014), bahwa ada lima tingkatan Kesiapan Personal mulai dari: Precontemplation; Contemplation; Preparation; Action dan terakhir Maintenance. Berdasarkan hasil penelitian menunjukan bahwa pengetahuan yang masuk pada tahap Pre - Contemplation tenaga Kesehatan Masyarakat yang memiliki pengetahuan tentang praktik mandiri kesehatan masyarakat hanya $20 \%$ dan sebanyak $80 \%$ tidak mengetahui tentang praktik mandiri. Hal ini dikarenakan Sarjana Kesehatan Masyarakat merupakan Pendidikan Akademik bukan Pendidikan Profesi sehingga tidak ada peraturan pelaksanaan dari Undang undang No.36 tahun 2014 yang mengatur tentang Praktik Profesi Kesehatan
Ciptaan disebarluaskan di bawah

Lisensi Creative Commons Atribusi-

NonKomersial-BerbagiSerupa 4.0

Internasional.

Masyarakat sehingga pada saat melaksanakan Pendidikan sarjana selama perkuliahan tidak pernah mendapat informasi tentang praktik mandiri kesehatan masyarakat. Sedangkan SKM yang mengetahui praktik mandiri sebanyak $20 \%$ ini merupakan SKM yang memahami secara umum konsep praktik kesehatan mandiri termasuk diantaranya aktivitas keterampilan yang berkaitan dengan ruang lingkung layanan esensial kesehatan masyarakat yang dapat dilaksanakan secara mandiri.

Bermitra dengan FKTP termasuk dalam praktik kesehatan masyarakat yang merupakan salah satu strategi agar dapat menerapkan ilmu pengetahuan dan teknologi untuk meningkatkan derajat kesehatan masyarakat. Berdasarkan hasil penelitian menunjukan bahwa sebagian besar (90\%) SKM tidak memiliki pengalaman dalam bermitra dengan FKTP. Hal ini dikarenakan keterbatasan informasi dan tidak adanya mekanisme kerjasama atau kemitraan antara SKM dengan FKTP dalam hal ini Praktik Dokter Keluarga sehingga SKM selama menempuh Pendidikan tidak mendapat informasi tentang kemitraan tersebut. FKTP atau Dokter Keluarga ini dalam konsep Jaminan Kesehatan Nasional merupakan Provider atau pemberi pelayanan kesehatan baik pelayanan yang bersifat perorangan (kuratif dan rehabilitatif) maupun pelayanan kesehatan masyarakat (preventif dan Promotif). Namun pada kenyataannya upaya kesehatan masyarakat tidak optimal dilaksanakan dikarenakan keterbatasan sumber daya termasuk tidak tersedia tenaga kesehatan masyarakat yang dapat mendukung target pelayanan.

Berdasarkan hasil penelitian Dewi (2016) tentang identifikasi pelaksanaan kegiatan promotif FKTP di Jember menyatakan bahwa bahwa FKTP yang melakukan pelayanan promotif hanya $(60 \%)$ hal ini dikarenakan karena tidak tersedia Sumber Daya Manusia Kesehatan (SDMK) yang dalam bidang Kesehatan

E-ISSN 2623-1204 P-ISSN 2252-9462 | 126 
JURNAL ILMU KESEHATAN BHAKTI HUSADA:

HEALTH SCIENCES JOURNAL, Vol. 10 No. 02, DeSEMBER 2019

DOI: $10.34305 / J I K B H . V 10 I 2.98$

masyarakat sebagai petugas khusus untuk pelayanan promotive, tidak ada alokasi biaya untuk pelayanan promotive, besar dana realisasi yang digunakan dalam pelayanan promotif rata- rata $2,3 \%$, belum ada $(100 \%)$ FKTP tidak melakukan pengkajian dalam pelayanan promotif dan hanya 3 FKTP yang memiliki dokumen perencanaan dan pelaksanaan dan seluruh FKTP tidak melakukan evaluasi. Dengan demikian unsur utama untuk dapat merealisasikan upaya promotif dan preventif di FKTP adalah ketersediaan tenaga kesehatan masyarakat dan selanjutnya untuk kesiapan dan kesediaan SKM sebagai tenaga kesehatan masyarakat penting diketahui.

Berdasarkan hasil penelitian menunjukan bahwa SKM seluruhnya siap dan bersedia bermitra dengan FKTP sebagai upaya untuk melaksanakan praktik kesehatan masyarakat. Kesiapan tenaga kesehatan masyarakat (SKM) secara personal untuk melaksanakan kemitraan dengan FKTP sebagai Personnel Readiness, yang dalam teori Linda R. Stanley (2014) masuk tahap Preparation yaitu Bersiap-siap untuk bertindak dan harus melakukan sesuatu tentang hal ini, sebisa yang dapat dilakukan. Semakin tinggi tingkat Kesiapan Personal, semakin tinggi keberhasilan implementasi program (Weiner BJ, 2009). Tingkatan kesiapan tenaga kesehatan masyarakat, dipengaruhi oleh faktor kepribadian atau personality dan lingkungannya, yang mempengaruhinya. Sedangkan unsur-unsur yang membentuk Kesiapan Tenaga Kesehatan masyarakat untuk menerapkan ilmu pengetahuan dan teknologi yaitu sikap atau attitude serta aktivitas dan sumberdaya.

Berdasarkan unsur-unsur kesiapan personal maka akan melahirkan kepercayaan diri atas kemampuan atau kompetensi yang dimiliki. Kepercayaan diri merupakan salah satu aspek kepribadian yang penting dalam kehidupan manusia termasuk kepercayaan diri tenaga kesehatan masyarakat (Budi Andayani, 1996).
Ciptaan disebarluaskan di bawah

Lisensi Creative Commons Atribusi-

NonKomersial-BerbagiSerupa 4.0

Internasional.

Kepercayaan terhadap kompetensi yang dimiliki merupakan unsur penting dalam bermitra dengan FKTP, karena hal ini akan mempengaruhi kualitas pelayanan kepada masyarakat. Kompetensi Tenaga Kesehatan Masyarakat menurut AIPTKMI (2012) memiliki 8 kompetensi utama yang mendukung pelayanan kesehatan pada tingkat pertama yaitu :

1. Mampu melaksanakan pelayanan kesehatan masyarakat tingkat pertama dengan melakukan: pengawasan status kesehatan, diagnosis dan investigasi masalah dan gangguan kesehatan masyarakat di wilayah kerjanya.

2. Mampu mengembangkan dan menerapkan kebijakan operasional dan perencanaan program untuk mendukung pelayanan kesehatan masyarakat

3. Mampu melaksanakan pendidikan dan pemberdayaan masyarakat tentang kesehatan dan mobilisasi masyarakat untuk identifikasi dan mengatasi masalah kesehatan masyarakat

4. Mampu melaksanakan pengawasan dan pengendalian efektivitas, aksesibilitas, dan kualitas pelayanan kesehatan masyarakat

5. Mampu mengkomunikasikan hasil kerjanya kepada masyarakat dan pemangku kepentingan pelayanan kesehatan masyarakat

6. Menguasai dasar-dasar keilmuan kesehatan masyarakat meliputi dasar biomedik, epidemiologi, biostatistik, ilmu sosial dan perilaku kesehatan, kesehatan lingkungan, kesehatan dan keselamatan kerja, administrasi dan kebijakan kesehatan, gizi kesehatan masyarakat, kesehatan reproduksi untuk dapat menjadi pelaksana dan pengelola pelayanan kesehatan masyarakat

7. Mampu mengambil keputusan efektif dan efisien dalam perencanaan, pengorganisasian, pelaksanaan, pengawasan, pengendalian dan penilaian program teknis, dan mengembangkan berbagai alternatif 
JURNAL ILMU KESEHATAN BHAKTI HUSADA:

HEALTH SCIENCES JOURNAL, Vol. 10 No. 02, DeSEMBER 2019 DOI: $10.34305 / J I K B H . V 10 I 2.98$

solusi untuk mengatasi masalah pelayanan kesehatan masyarakat

8. Bertanggung jawab secara mandiri di bidang tugasnya, bersikap kritis dan bertanggung jawab terhadap kerja kelompok.

Berdasarkan uraian kompetensi tersebut, upaya Pendidikan SKM dilakukan dengan model pemberian pengalaman (experiential Learning) kepada mahasiswa melalui Program Pengalaman Belajar Lapangan. Kegiatan ini merupakan implementasi dari praktik kesehatan masyarakat melalui kegiatan identifikasi masalah, perumusan masalah prioritas, penentuan alternatif pemecahan masalah, intervensi, evaluasi dan memberikan rekomendasi untuk keberlanjutan program di masyarakat. Hasil ini sejalan dengan penelitian Ahmad Syafiq (2006) bahwa pembelajaran berbasis lapangan dipersepsi sebagai pengalaman belajar yang paling penting dan bahwa soft-skill adalah keterampilan yang sangat dihargai dan relevan di dunia kerja nyata bagi lulusan Program Studi S1 Kesehatan Masyarakat (Ahmad Syafiq, 2006). Dengan demikian upaya ini data meningkatkan kepercayaan diri terhadap kemampuan dan kompetensi yang dimiliki oleh SKM untuk melaksanakan praktik mandiri dan bermitra dengan FKTP dalam upaya promotif dan preventif.

\section{Kesimpulan}

Berdasarkan hasil penelitian dapat disimpulkan bahwa SKM yang mandiri atau tidak terikat dengan FKTP di Kabupaten Kuningan sebagian besar $(80 \%)$ belum memiliki STR, sebagian besar $(85 \%)$ belum menjadi anggota IAKMI, dalam hal kesiapan bermitra dengan FKTP maka SKM sebagian besar tidak mengetahui praktik mandiri SKM, sebagian besar tidak memiliki pengalaman bermitra dengan FKTP (90\%), seluruh SKM siap bermitra dan seluruh SKM memiliki kepercayaan diri dalam bermitra dengan FKTP. Saran
Ciptaan disebarluaskan di bawah

Lisensi Creative Commons Atribusi-

NonKomersial-BerbagiSerupa 4.0

Internasional

diharapkan SKM meningkatkan kompetensi untuk mendapatkan STR dan tergabung dalam organisasi profesi IAKMI dan bagi iakmi dan AIPTKMI harus menyusun panduan praktik kesehatan masyarakat dan kemitraan dengan FKTP sebagai bagian dari praktik mandiri kesehatan masyarakat.

\section{Referensi}

AIPTKMI. (2014). Naskah Akademik Pendidikan Tinggi Kesehatan Masyarakat. In Seminar AIPTKMI. Jakarta.

Andayani, B., \& Afiatin, T. (1996). Konsep Diri, Harga Diri, dan Kepercayaan Diri Remaja. Jurnal Psikologi, 23(1996).

Anita, B., \& Febriawati, H. (2019). Puskesmas Dan Jaminan Kesehatan Nasional. Deepublish.

Bruner, J. S. (1957). On perceptual readiness. Psychological Review, 64(2), 123.

Dewi, R. K. (2015). Identifikasi Pelayanan Promotif pada Fasilitas Kesehatan Tingkat Pertama Program Jaminan Kesehatan Nasional (Studi pada Klinik Pratama dan Dokter Praktik Perorangan di Kabupaten Jember).

Dewi, R. K., Nuryadi, N., \& Sandra, C. (2016). Identifikasi Pelayanan Promotif pada Fasilitas Kesehatan Tingkat Pertama Program Jaminan Kesehatan Nasional (Identification of Promotive Services In Primary Health Care Facility of National Health Insurance Program). Pustaka Kesehatan, 4(2), 307-315.

Edwards, R. W., Jumper-Thurman, P., Plested, B. A., Oetting, E. R., \& Swanson, L. (2000). Community readiness: Research to practice. Journal of Community Psychology, 28(3), 291-307.

IAKMI. (2018). Pedoman Pendidikan Berkelanjutan

Berkelanjutan. IAKMI. Keprofesian

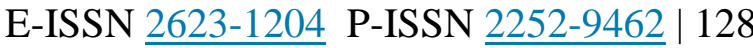


JURNAL ILMU KESEHATAN BHAKTI HUSADA:

HEALTH SCIENCES JOURNAL, Vol. 10 No. 02, DeSEMBER 2019

DOI: $10.34305 / J I K B H . V 10 I 2.98$

Mujiati, M., \& Yuniar, Y. (2017). Ketersediaan Sumber Daya Manusia Kesehatan pada Fasilitas Kesehatan Tingkat Pertama dalam Era Jaminan Kesehatan Nasional di Delapan Kabupaten-Kota di Indonesia. Media Penelitian Dan Pengembangan Kesehatan, 26(4), 201-210.

Putri Auzoer Atia. (2015). Analisis Sistem Pelaksanaan Pelayanan Promotif Preventif Dalam Era Jaminan Kesehatan Nasional (JKN) Di Puskesmas Bungus Padang Tahun 2015. UPT. Perpustakaan Unand.

Rahma, A., Arso, S. P., \& Suparwati, A. (2017). Implementasi Fungsi Pokok Pelayanan Primer Puskesmas Sebagai Gatekeeper Dalam Program JKN (Studi di Puskesmas Juwana Kabupaten Pati). Jurnal Kesehatan Masyarakat (e-Journal), 3(3), 1-11.

Stanley, L. R. (2014). Community readiness for community change. Tri-Ethnic Center for Prevention Research, Fort Collins.

Sudirwan, J., \& Pangestu, H. (2015). Kesiapan Dosen untuk Mengembangkan Keterampilan Kerja, Studi Kasus Pada Binus University. In Paper dalam Seminar Nasional Teknologi Informasi dan Komunikasi.

Sukowati, S., \& Shinta, S. (2003). Peran Tenaga Kesehatan Masyarakat dalam Mengubah Perilaku Masyarakat Menuju Hidup Bersih dan Sehat. Media Penelitian Dan Pengembangan Kesehatan, 13(2 Jun).

Syafiq, A., \& Fikawati, S. (2007). Tracer Study: Melacak Jejak Lulusan FKM UI (Hasil Studi Kualitatif Tracer Sarjana Kesehatan Masyarakat FKM UI 2006). Kesmas: National Public Health Journal, 1(6), 252258.
Ciptaan disebarluaskan di bawah

Lisensi Creative Commons Atribusi-

NonKomersial-BerbagiSerupa 4.0

Internasional.

Undang-undang. No 36 tahun 2014 tentang Tenaga Kesehatan (2014). Indonesia.

Vijriyanti, L. (2018). Identifikasi Medication Error Dalam Proses Prescribing, Transcribing Dan Dispensing Resep Racikan Di Puskesmas Kabupaten Banyumas Wilayah Selatan. UNIVERSITAS MUHAMMADIYAH PURWOKERTO.

Weiner, B. J. (2009). A theory of organizational readiness for change. Implementation Science, 4(1), 67. 